\title{
Advantages of Phase Angle in Evaluating Physical Vitality Level
}

\author{
Katsunori Fujii, Yuki Takeyama \\ Graduate School of Business Administration and Computer Science, Aichi Institute of Technology, Toyota-City, Aichi, Japan
}

\section{Email address:}

fujii@aitech.ac.jp (K. Fujii), Yuki319takeyama@yahoo.co.jp (Y. Takeyama)

\section{To cite this article:}

Katsunori Fujii, Yuki Takeyama. Advantages of Phase Angle in Evaluating Physical Vitality Level. American Journal of Sports Science. Vol. 8, No. 3, 2020, pp. 56-61. doi: 10.11648/j.ajss.20200803.12

Received: July 4, 2020; Accepted: July 20, 2020; Published: July 28, 2020

\begin{abstract}
Phase angle ( $\mathrm{PhA})$ has become a sudden focus of attention in recent years. However, much remains unknown about its relationship with health indicators. If it is an indicator derived through bioelectrical impedance analysis (BIA), its meaning as a simple health indicator can probably be established. In fact, an indicator of senescence called "vital age" has been proposed. However, this vital age is derived from multivariate factors and so cannot be called a simple indicator. Accordingly, while presenting the term physical vitality as one determinant of health, we defined physical vitality in the sense of conceptualizing the body's internal control mechanism power that governs the life force. That power regulates health, which is an indicator of the driving force (life force) of human life. In this study we compared phase angle in high school sports club members and general student controls, and showed that the height of the phase angle in club members reflects their physical vitality. An attempt was then made to position phase angle as an indicator of physical vitality. Specifically, we evaluated the phase angles of individual club members by constructing a span evaluation chart with age of phase angle and applying individual club members to that evaluation chart, with general high school students as a control group. With this ability to evaluate the phase angles of individuals, rather than showing that phase angle was high in all club members we were able to grasp the physical vitality levels of health factors possessed by each individual.
\end{abstract}

Keywords: Phase Angle, Physical Vitality Level, Bioelectrical Impedance Analysis (BIA), Span Evaluation Chart with Age

\section{Introduction}

The development of medicine has depended on a foundation of humans' natural healing power, nothing more and nothing less. Humans could be said to adopt medical practices that utilize natural healing power centered on immune mechanisms, all based on the physiological homeostasis that is originally possessed by humans. In short, physical vitality, like the life force possessed by humans, controls our natural healing power. Physical vitality in this case is the human power to live, and can be understood as the power of an essential internal control mechanism in humans that is like a life force. However, while the term physical vitality has not been used in this sense previously, there is a history of using the term "vital age." In fact, Tanaka et al. [1] presented the term vital age in the sense of level of health. Tanaka et al. [1] defined vital age as an indicator constructed by applying a principal component model to evaluate biological age as an indicator of senescence; that is, to evaluate the level of senescence. Therefore, vital age is an indicator that comprehensively evaluates various health-related factors that determine levels of human health and senescence [2, 3]. Hamasaki et al. [4] stated that since it is a scale that can be easily understood even by older adults, vital age can be an effective evaluation indicator in older adults attempting to improve their daily living habits and maintain their level of health.

Vital age, however, illuminates levels of senescence and health on a chronological time scale from a principal component model, or factors that require multiple variates. Rather than evaluating vitality, or the human power to live, with multiple variates, it would be better to judge the level of health by depending on detailed medical examinations, which can be done more accurately. In other words, simple methods are preferable in evaluating the level of health or vitality. By using the term physical vitality, the body's internal control mechanism power was conceptualized as an essential element and life force to derive the concept of vital age using a simpler 
method. Naturally, this physical internal control mechanism power is regulated by the brain, and this concept can be defined as the physical vitality that regulates health, which is an indicator of the driving force for human life. The possibility of an indicator that can evaluate physical vitality, which governs this concept of physical internal control mechanism power, can be presented.

There is an indicator of nutritional status that has become a sudden focus of attention in recent years, an indicator that reflects the level of cellular activity. That indicator is called phase angle $(\mathrm{Ph} \mathrm{A})$, and it can be easily measured with bioelectrical impedance analysis (BIA). This indicator is the impedance $(Z)$ of the vector value expressed with the resistance (R) originating from the intracellular and extracellular fluid, the reactance $(\mathrm{Xc})$ originating from the cell membrane, and the square root of the square of $\mathrm{R}$ and the square of Xc. Likening the cell membrane to a condenser, reactance $(\mathrm{Xc})$ produces a deviation in the lag phase in the current over time with voltage. Hence, phase angle is the arc tangent of Xc divided by R. Phase angle illuminates the state of the cell membrane and intracellular fluid, showing low values with increased dead cells or decreased cell permeability, and high values with increases in cells with high activity levels It is reported to be particularly useful in predicting the survival rate in cancer patients [5]. Tsutsumi et al. [6] stated that there is significant correlation between the seriousness of the disease and phase angle in patients with advanced disease, but that uniform conclusions have not been reached on whether it is effective as a prognostic indicator. However, from the potential for high utilization as a nutritional indicator, it can be inferred that phase angle shows the level of physical activity. Moreover, since phase angle illuminates the relationship between the intracellular and extracellular fluid, derived from resistance $(\mathrm{R})$ and reactance $(\mathrm{Xc})$, it is taken to be a quality parameter of muscle [7]. According to Yamada et al. [8], phase angle increased with increased muscle mass and increased intracellular fluid in muscle. Uemura et al. [9] indicated the possibility that it could be a comprehensive indicator in evaluating frailty and sarcopenia in older adults, as well as changes in disease prognostic indicators and physical health. Thus, phase angle can probably be seen as physical vitality level, which is one element of physical indices.

In fact, there is not much research on phase angle seen as an indicator of physical vitality level. For example, there is almost no research on aging. About the only study is one by Barbosa-Silva et al. [10] on age-related changes in Americans. Fujii and Hayakawa [11] conducted the only analysis of age-related changes in Japanese schoolchildren ( $1^{\text {st }}$ grade of elementary school to $3^{\text {rd }}$ grade of middle school) and verified the pubertal peak (age at maximum peak velocity; MPV). Their findings showed that age at MPV of phase angle was a critical point for level of health. That is, if physical vitality is defined as a determinant of health, age-related change in phase angle can be seen as age-related change in physical vitality. The age at MPV can then be taken as a critical point in physical vitality. Consequently, if physical vitality can be easily determined with phase angle, an understanding of health can be reached more easily. In this study, we selected high school students from a powerful sports club who possess strong physical ability, in the sense that they embody physical activity level. With general high school students as a control group, phase angle calculated with BIA was used to analyze the level of phase angle in the sports club. By comparing the phase angle level of the group with physical ability connoting physical vitality with the phase angle in a group a general level of activity, we examined the effectiveness of phase angle as a means to estimate the level of physical vitality.

\section{Methods}

\subsection{Subjects and Materials}

Physical composition was measured in first and second year students of a high school in Prefecture K from 2018 to 2019. Longitudinal data on 159 male and 193 female high school students were obtained. A breakdown is shown in Table 1. The subjects' dates of birth were also recorded and their precise age on the date of the measurements was calculated. The details of the survey and measurements were explained to the subjects and their parents in advance, and their informed consent was obtained. None of the subjects had any acute or chronic diseases.

\subsection{Measurement of Phase Angle (PhA)}

Height, weight, body fat percentage, fat mass, and muscle mass were measured using bioelectrical impedance analysis (BIA) with a Tanita MC-780. Resistance (R), reactance (Xa), impedance $(\mathrm{Z})$, and phase angle $(\mathrm{PhA})$ were also measured.

\subsection{Analytical Procedures}

1) Normality was tested in each school year for the average age-related change in phase angle from the first to the second year in high school. General students were selected for the control group and baseball and boating club members were selected for the powerful sports club group. Phase angle was compared in the two groups in each year.

2) An age-related evaluation chart was constructed with the application of least squares approximation polynomials for phase angle in the control group of general students for the period from the first to second year of high school.

3) The phase angles in the baseball and boating club members were applied to the constructed age-related evaluation chart and the distribution of phase angles was analyzed.

Table 1. Statistics of height, weight, BMI and Phase angle for first and second year in high school.

\begin{tabular}{lllll}
\hline & \multicolumn{2}{l}{ Boys $(\mathbf{n = 1 5 9})$} & \multicolumn{3}{l}{ Girls $(\mathbf{n}=\mathbf{1 9 3})$} \\
\cline { 2 - 5 } & $\begin{array}{l}\text { First year } \\
(\mathbf{n}=\mathbf{6 7})\end{array}$ & $\begin{array}{l}\text { Second year } \\
(\mathbf{n}=\mathbf{9 2})\end{array}$ & $\begin{array}{l}\text { First year } \\
(\mathbf{n}=\mathbf{7 7})\end{array}$ & $\begin{array}{l}\text { Second year } \\
(\mathbf{n}=\mathbf{1 1 6})\end{array}$ \\
\hline Height & $171.17 \pm 6.04$ & $171.61 \pm 6.71$ & $158.43 \pm 5.47$ & $158.43 \pm 5.03$ \\
Weight & $60.69 \pm 9.16$ & $64.23 \pm 9.97$ & $51.82 \pm 5.90$ & $51.41 \pm 6.55$ \\
BMI & $20.67 \pm 2.58$ & $21.78 \pm 2.96$ & $20.67 \pm 2.28$ & $20.47 \pm 2.33$ \\
Phase angle & $6.65 \pm 0.67$ & $6.81 \pm 0.61$ & $5.61 \pm 0.52$ & $5.61 \pm 0.53$ \\
\hline
\end{tabular}




\section{Results}

\subsection{Test of Normality of Phase Angle in High School Students}

Normality was tested from the phase angle statistics for each year in first and second year male and female high school students (Table 1). There are methods to investigate kurtosis and skewness from the distribution of data in testing normality, but in this study the analysis was done with application of a normal distribution function from the actual phase angle frequency distribution. The results are shown in Tables 2 and 3. They show no significant difference in a $\chi^{2}$ test between the theoretical valued derived from the normal distribution function of phase angle and the actual values in the first and second year male and female high school students. Normality was seen.
Figures 1 and 2 show the frequency distributions of phase angle in first year male and female high school students, and it is seen that they fit well with the normal distribution function.

Table 2. Test of normality of Phase angle value for first and second year.

\begin{tabular}{lll}
\hline & Boys & Girls \\
\hline $\begin{array}{ll}\text { First } \\
\text { year }\end{array}$ & $f(x)=\frac{0.2 \times 67}{\sqrt{2 \pi} \times 0.67} e^{-\frac{\left(x_{i}-6.65\right)^{2}}{2(0.67)}}$ & $f(x)=\frac{0.2 \times 77}{\sqrt{2 \pi} \times 0.52} e^{-\frac{\left(x_{i}-5.60\right)^{2}}{2(0.52)}}$ \\
$\begin{array}{l}\text { Second } \\
\text { year }\end{array}$ & $f(x)=\frac{0.2 \times 92}{\sqrt{2 \pi} \times 0.62} e^{-\frac{\left(x_{i}-6.81\right)^{2}}{2(0.62)}}$ & $f(x)=\frac{0.2 \times 116}{\sqrt{2 \pi} \times 0.53} e^{-\frac{\left(x_{i}-5.61\right)^{2}}{2(0.53)}}$ \\
\hline
\end{tabular}

Table 3. $\chi^{2}$ value for first and second year in boys and girls.

\begin{tabular}{lll}
\hline & Boys & Girls \\
\hline First year & 33.91 & 11.50 \\
Second year & 17.53 & 9.40 \\
\hline
\end{tabular}

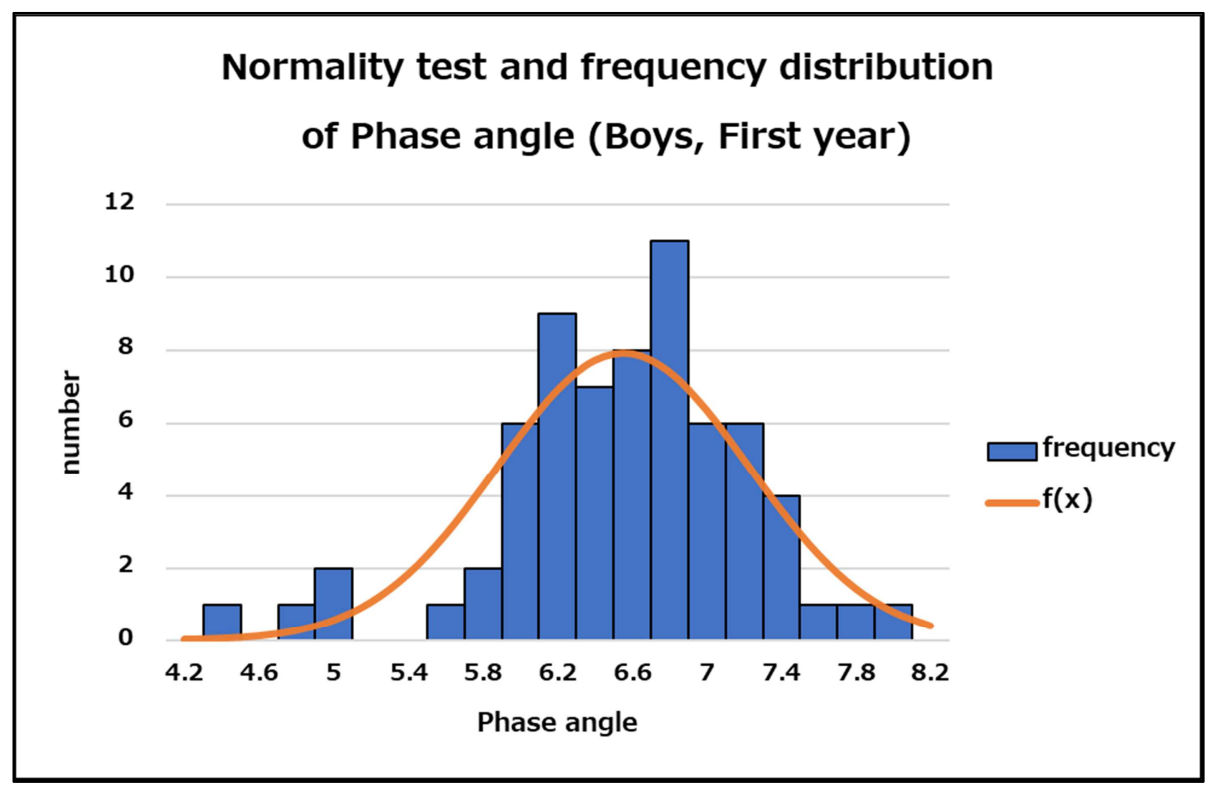

Figure 1. Normality test and frequency distribution of Phase angle in first year (Boys).

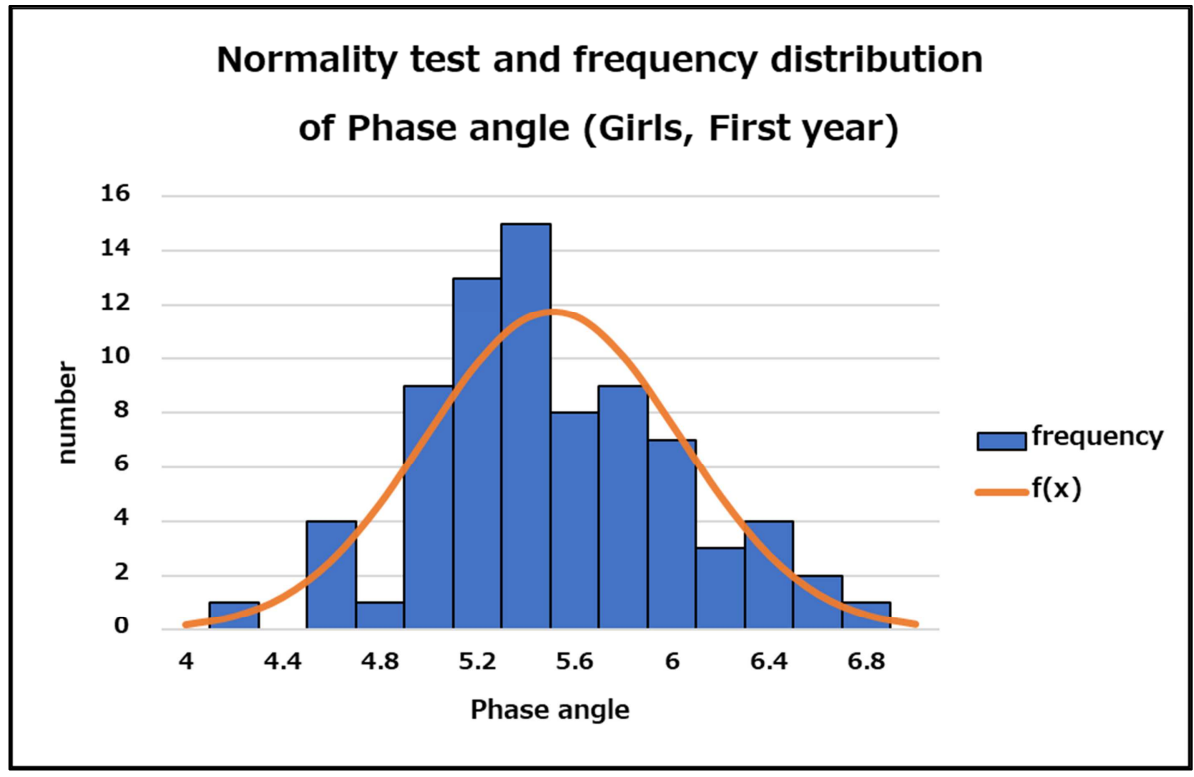

Figure 2. Normality test and frequency distribution of Phase angle in first year (Girls). 


\subsection{Comparison of Phase Angle in the Sports Clubs and Control Group}

Tables 4 and 5 show the phase angle statistics in the sports clubs and control group. According to this, significant differences $(\mathrm{P}<0.01)$ in phase angle are seen between the control group and sports clubs in first and second year students in both boys and girls. This shows that the phase angle was higher in the sports clubs.

\subsection{Phase Angle Determinations in the Sports Clubs Based on the Phase Angle Age-related Evaluation Chart}

Least squares approximation polynomials were applied to the mean value and standard deviation for phase angle in a two-year span for first and second high school students to determine age-related changes in phase angle. Figures 3 and 4 are the span evaluation charts with age for phase angle in boys and girls described with least squares approximation polynomials. When the boys and girls in the sports clubs are applied to those span evaluation charts, the phase angle distribution is seen to be clearly higher. As is clear from these figures, phase angle evaluations are shown in individual boys and girls in sports clubs, and the phase angles of nearly all of the students who belonged to powerful sports clubs were seen to be high.

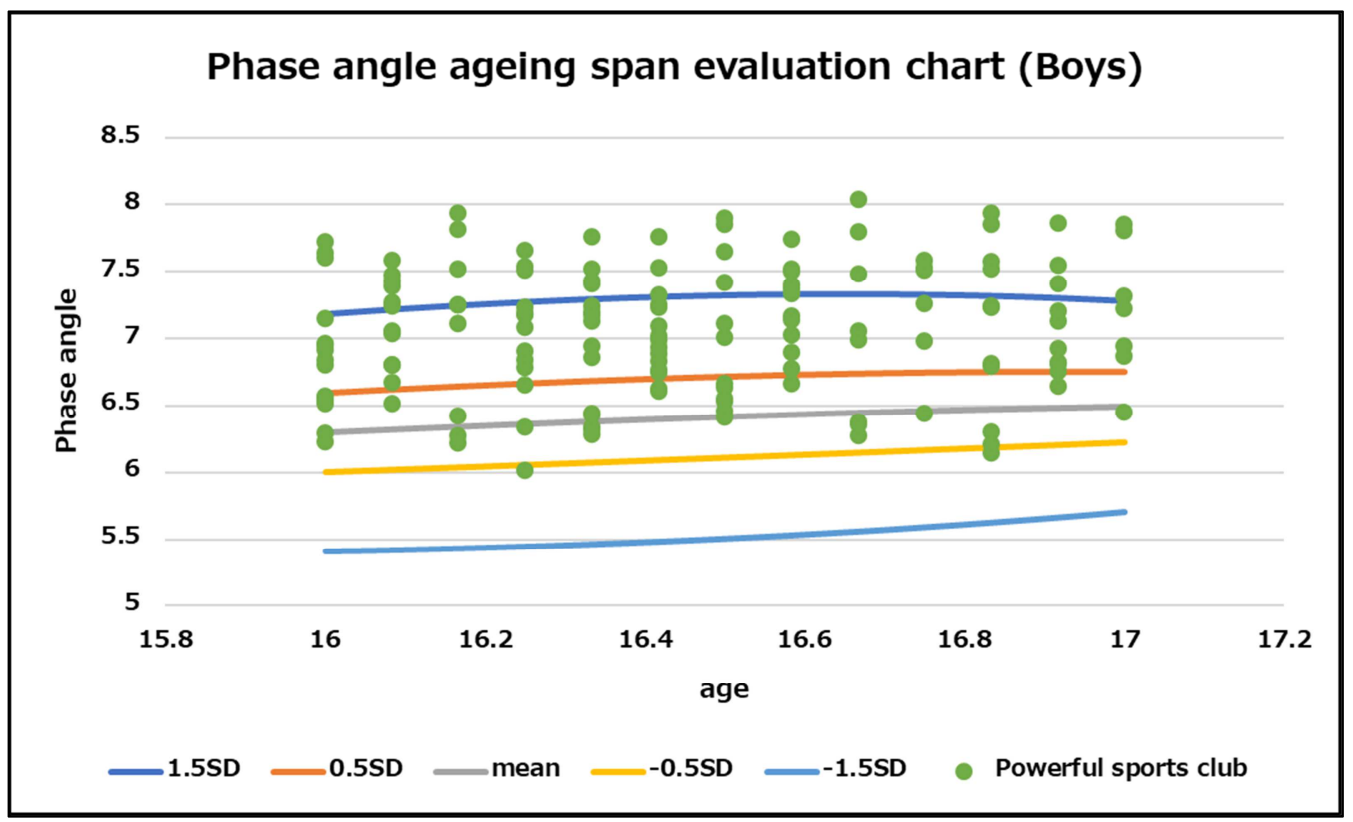

Figure 3. Application to aging span evaluation chart (Boys, Powerful sports club).

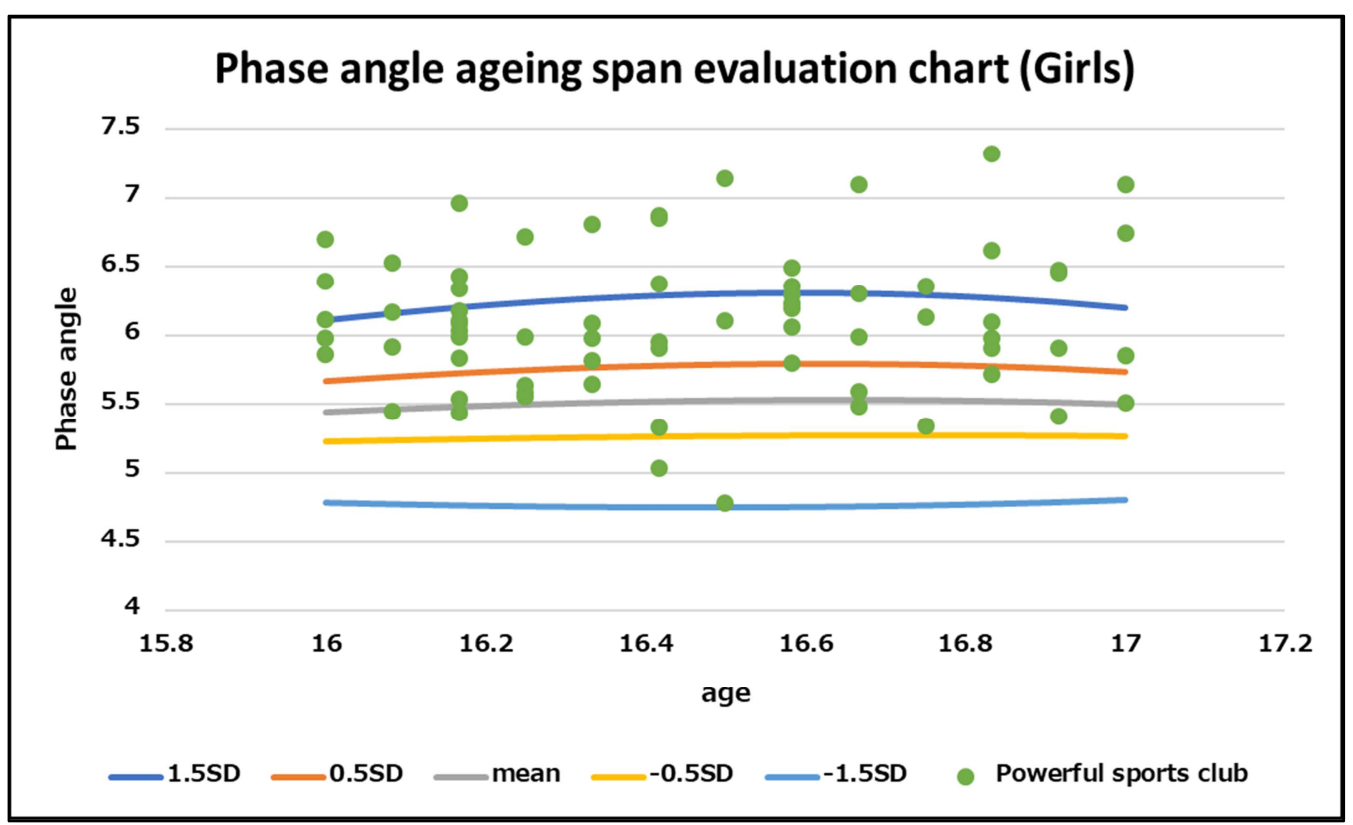

Figure 4. Application to aging span evaluation chart (Girls, Powerful sports club). 
Table 4. Statistics of height, weight, BMI and Phase angle by age group (Boys).

\begin{tabular}{lllllll}
\hline \multirow{2}{*}{ Boys } & First year $(\mathbf{n}=\mathbf{6 7})$ & & \multicolumn{3}{c}{ Second year $(\mathbf{n}=\mathbf{9 2})$} \\
\cline { 2 - 7 } & Control $(\mathbf{n}=\mathbf{2 5})$ & Powerful sports club $(\mathbf{n}=\mathbf{4 2})$ & $\boldsymbol{p}$ & Control $(\mathbf{n}=\mathbf{5 3})$ & Powerful sports club $(\mathbf{n}=\mathbf{3 9})$ & $\boldsymbol{p}$ \\
\hline Height & $169.95 \pm 4.31$ & $171.89 \pm 6.80$ & n.s. & $171.35 \pm 6.56$ & $171.97 \pm 6.99$ \\
Weight & $54.78 \pm 7.04$ & $64.21 \pm 8.49$ & $* *$ & $62.34 \pm 10.49$ & $66.81 \pm 8.70$ & n.s. \\
BMI & $18.96 \pm 2.31$ & $21.69 \pm 2.19$ & $* *$ & $21.20 \pm 3.23$ & $22.56 \pm 2.36$ & $*$ \\
Phase angle & $6.18 \pm 0.69$ & $6.94 \pm 0.47$ & $* *$ & $6.49 \pm 0.53$ & $7.24 \pm 0.43$ & $*$ \\
\hline
\end{tabular}

$*: \mathrm{p}<0.05, * *: \mathrm{p}<0.01$

Table 5. Statistics of height, weight, BMI and Phase angle by age group (Girls).

\begin{tabular}{lllllll}
\hline \multirow{2}{*}{ Girls } & First year $(\mathbf{n}=\mathbf{7 7})$ & & \multicolumn{3}{c}{ Second year $(\mathbf{n}=\mathbf{1 1 6})$} \\
\cline { 2 - 7 } & Control $(\mathbf{n}=\mathbf{4 8})$ & Powerful sports club $(\mathbf{n = 2 9})$ & $\boldsymbol{p}$ & Control $(\mathbf{n}=\mathbf{9 6})$ & Powerful sports club $(\mathbf{n}=\mathbf{2 0})$ & $\boldsymbol{p}$ \\
\hline Height & $158.33 \pm 5.08$ & $158.60 \pm 5.15$ & n.s. & $158.51 \pm 5.31$ & $158.08 \pm 3.44$ & n.s. \\
Weight & $52.56 \pm 5.83$ & $50.60 \pm 5.90$ & n.s. & $51.14 \pm 6.63$ & $52.67 \pm 6.15$ & n.s. \\
BMI & $20.99 \pm 2.31$ & $20.13 \pm 2.17$ & n.s. & $20.35 \pm 2.37$ & $21.05 \pm 2.11$ & n.s. \\
Phase angle & $5.44 \pm 0.46$ & $5.90 \pm 0.48$ & $* *$ & $5.50 \pm 0.47$ & $6.14 \pm 0.49$ & $* *$ \\
\hline
\end{tabular}

$*: \mathrm{p}<0.05, * *: \mathrm{p}<0.01$

\section{Discussion}

Looking at the phase angle in the sports club members and the control group in the male high school students in this study, we see that the phase angle was about 7.0-7.3 in both first and second year students in the sports clubs, and about 6.3-6.5 in the control group. A significant difference was clearly seen between the groups, and it was confirmed that the phase angle was higher in the sports club members. In a study by Barbosa et al. [10] with western subjects, phase angle was reported to be $7.9^{\circ} \pm 0.47$ in $18-20$-year-old males and $7.04^{\circ} \pm 0.85$ in females. Phase angle was reported to be lower in Asians than in African-Americans and Hispanics. Certainly, western people are physically larger and higher BMI is considered to be one reason for the comparatively lower phase angle in Asians, but it is probably not a simple composition in which phase angle becomes higher in people who are physically larger. The phenomenon is similar to the previous mistaken concept that taller people have higher athletic ability shown by Fujii [12]. It must be made clear that high athletic ability is not dependent on tall height but is an independent phenomenon. With regard to this misunderstanding, the significance shown with a weak correlation in a correlation analysis of height and grip strength could be considered to come from the relationship with athletic ability. Therefore, in correlation analyses between phase angle and BMI or muscle strength, the significance with low correlation that was shown may be conjectured to have come from the correlation between physical size and phase angle. In fact, it is a figure derived from body fat mass and muscle mass by BIA, and so a composition in which a low correlation with these elements is derived cannot be ruled out.

Therefore, if phase angle is considered to be an independent phenomenon, could it be positioned as one determinant of health that estimates physical vitality? The fact that the phase angle of club members was higher than that of general students in the present results could certainly be said to be a phenomenon similar to the relationship between Caucasoids and Mongoloids in physical size. However, it is conjectured that phase angle illuminated the physical vitality level dependent on the physical ability originally possessed by sports club members. Phase angle does not show that the genetic element of physical vitality in Caucasoids is superior to that in Mongoloids. Matsumoto [13] aimed the importance of the gene polymorphisms of aldehyde dehydrogenase 2 (ALDH2). Caucasoids are better able to break down alcohol because of the activity of this gene, whereas Mongoloids have lower activity. One could say that this is a different phenomenon from physical vitality, but inherent genetic physical vitality could be ascertained if there is a genetic characteristic of tolerating alcohol well. In fact, in a study by Schmidt et al. [14] with German subjects, the phase angle was reported to be $7.02^{\circ} \pm 0.61$ in adult males with a BMI of $21.93 \pm 1.58 \mathrm{~kg} / \mathrm{m}^{2}$ and $5.91^{\circ} \pm 0.59$ in adult females with a BMI of $21.61 \pm 1.71 \mathrm{~kg} / \mathrm{m}^{2}$. Hence, since the effect of BMI can be eliminated, the phase angle of male and female Japanese high school students in this study is thought to be somewhat low. Even though we are speaking of high school students, the phase angle of the sports club members is still about the same. If this is thought to be a racial difference, it can be understood as a genetic physical activity level. Hence, while the superior physical strength and athletic abilities of sports club members have genetic factors, it may be that high phase angle can be taken not as a phenomenon that is dependent on physical ability, but as a phenomenon of physical vitality level.

The vital age proposed by Tanaka et al. $[1,2]$ is a concept constructed with the application of a principal component analysis model as an indicator of senescence, but it may be viewed as an indicator derived from many elements that estimate physical abilities. If the concept of vital age is derived from many of the factors that regulate health, vital age could already be called an independent phenomenon. Therefore, the phase angle of individual sports club members was evaluated based on the span evaluation chart with age for phase angle in this study, and the individual physical vitality level could be grasped. The factors that determine health in the sports club members could be verified with certainty, which suggests the potency of phase angle. As an aside, Rodríguez et al. [15] reported a correlation between phase angle and grip strength in Colombian men $(\mathrm{r}=0.58)$. This finding is a phenomenon similar 
to the relationship between BMI and phase angle, and is grasped myopically as that phase angle is high because physical strength and athletic ability are high in sports club members. This phenomenon has the same composition as the vital age of Tanaka et al. [1, 2], and is an indicator basically derived from many health-related factors, and so the fact that a correlation was seen between BMI and physical strength and athletic ability may be considered obvious. Of course, phase angle also has the same composition, and consequently should be considered an independent phenomenon if it is a factor that regulates health the same as vital age.

Fujii and Hayakawa [11] analyzed the age-related change in phase angle and found that the age at MPV of phase angle is 13.5 years old, which suggests that this age is a critical point in acquiring health. If physical vitality is a critical point, and considering that this is the period when the immune system thymus shows its peak in puberty, it would be important to closely observe people's relationship with illness with the critical point of physical vitality as a borderline. At the same time, it is a period when a physical vitality level closer to that of adults is secured. Considering the height of the phase angle in the sports club members in this study, raising the physical vitality level by encouraging exercise could lead to the acquisition of health and prevention of disease.

\section{Conclusion}

While presenting the term physical vitality as one determinant of health, we defined physical vitality in the sense of conceptualizing the body's internal control mechanism power that governs the life force. That power regulates health, which is an indicator of the driving force (life force) of human life. In this study we compared phase angle in high school sports club members and general student controls, and showed that the height of the phase angle in club members reflects their physical vitality. An attempt was then made to position phase angle as an indicator of physical vitality. Specifically, we evaluated the phase angles of individual club members by constructing a span evaluation chart with age of phase angle and applying individual club members to that evaluation chart, with general high school students as a control group. With this ability to evaluate the phase angles of individuals, rather than showing that phase angle was high in all club members we were able to consider the physical vitality levels of health factors possessed by each individual.

\section{References}

[1] K. Tanaka, Y. Matsuura, F. Nakadomo and E. Nakamura, "Assessment of vital age of Japanese woman by principal component analysis," Japan Journal of Physical Education, Health and Sport Sciences, 35, pp. 121-131, 1990.

[2] K. Tanaka, T. Yoshimura, K. Maeda, F. Nakadomo, N. Takeshima, K. Asao, M. Takeda, Y. Kumazaki, H. Watanabe and T. Hiyama, "Validity of CHD Risk Factor-dependent "Vital Age" as an Index of Health and Aging Status," The
Journal of Japan Atherosclerosis Society, Vol. 19, No. 4, pp. 303-310, 1991.

[3] K. Tanaka, H. Sakai, M. Eto, T. Tsujimoto, S. Jung, R. So, Y. Osuka, M. Nemoto and S. Seino, "Vital age in middle-aged and older men and women with regular ten-pin bowling habits," Bull. Inst. Health \& Sport Sci., Univ. of Tukuba, 35, pp. 73-80, 2012.

[4] A. Hamasaki, Y. Osuka, D. Kubota, Y. Kawate, H. Kobayashi and K. Tanaka, "Combined effects of nutritional supplements and exercise habituation on vital age of middle-aged and older adults," Japanese Journal of Health Promotion, Vol. 19, No. 2, pp. 127-136, 2017.

[5] D. Gupta, C. A. Lammersfeld, P. G. Vashi, J. King, S. L. Dahlk, J F. Grutsch, and C. G. Lis, "Bioelectrical impedance phase angle in clinical practice - implications for prognosis in stage IIIB and IV non-small cell lung cancer,” BMC Cancer, pp. 1-6, 2009.

[6] R. Tsutsumi, J. Oto, K. Fukunaga, M. Chikugo, M. Sebe, M. Iuchi, Y. Tsutsumi, M. Nishimura and H. Sakaue, "Usefulness and limitation of body composition assessment in critical ill patients," Journal of Japanese Society for Parenteral and Enteral Nutrition, 31 (3), pp. 803-806, 2016.

[7] Sardinha, L. B. "Physiology of exercise and phase angle: another look at BIA," European Journal of Clinical Nutrition, 72, pp. 1323-1327, 2018.

[8] Y. Yamada, B. Buehring, D. Krueger, R. M. Anderson, D. A. Schoeller, and N. Binkley, "Electrical Properties Assessed by Bioelectrical Impedance Spectroscopy as Biomarkers of Age-related Loss of Skeletal Muscle Quantity and Quality," The Journals of Gerontology: Series A, Vol. 72, Issue 9, pp. 1180-1186, 2017.

[9] K. Uemura, M. Yamada, K. Saho and H. Okamoto, "Association of Bio-impedance Phase Angle and Physical Activity Level in Older Adults," Journal of Physical Therapy Research, 46 (3), pp. 143-151, 2019.

[10] M C. G. Barbosa-Silva, A JD. Barros, J. Wang, S. B. Heymsfield and R. N. Pierson Jr, "Bioelectrical impedance analysis: population reference values for phase angle by age and sex," The American Journal of Clinical Nutrition, 82, pp. 49-52, 2005.

[11] K. Fujii and K. Hayakawa, "Composition of Change in Phase Angle with Age in Japanese Children," American Journal of Sports Science, 8 (1), pp. 10-16, 2020.

[12] K. Fujii, "Exploration of The Human Resource Elements of Sports Athletes: Sports Talent and Tall Height," Japan Society for Production Management, Vol. 27, No. 1, pp. 1-166, 2020.

[13] A. Matsumoto, "Fundamental Properties of Aldehyde Dehydrogenase 2 (ALDH2) and the Importance of the $A L D H 2$ Polymorphism," Japanese Journal of Hygiene, Vol. 71, No. 1, pp. 55-68, 2016.

[14] Schmidt, S. C., Bosy-Westphal, A., Niessner, C. and Woll, A. "Representative body composition percentiles from bioelectrical impedance analyses among children and adolescents. The MoMo study," Clin. Nutr, 38 (6), pp. 2712-2720, 2018.

[15] Rodríguez-Rodríguez, F., Cristi-Montero, C., González-Ruíz, K., Correa-Bautista, J. E., and Ramírez-Vélez, R. "Bioelectrical impedance vector analysis and muscular fitness in healthy men," Nutrients, 8 (407), pp. 1-9, 2016. 